\title{
Dream and motivation: a psychobiological approach
}

\author{
R. J. Katz and M. Steiner \\ Mental Health Research Institute, Department of Psychiatry, \\ University of Michigan Medical Center, Ann Arbor, Michigan 48109, USA
}

\begin{abstract}
Several lines of evidence point to the dream as a mediator of incentive phenomena. We review herein evidence from ontogenetic studies of the pleasure reaction, phylogenetic studies of the evolution of intelligence, studies of brain stimulation and recording, and clinical observations. These all suggest that it is possible to identify an evolutionary specialization of pleasure that (a) has served to mediate cognitive phenomena and (b) that the pontine noradrenergic locus coeruleus nucleus and its projections may play a role in this mediation.
\end{abstract}

'In everyone resides a certain species of desires, that are terribly savage and irregular-and this indeed, becomes manifest in sleep.'

\section{Plato, Dialogues}

'The dreams of small children are simple wish fulfillments and therefore, in contradiction to the dreams of adults, of very little interest. They are no puzzles, but are naturally of utmost importance as proof that in its core every dream is a wish fulfillment.'

\section{FREUD, Interpretation of Dreams}

Dreams, by their nature, are continually present reminders of the complexity of mental life. All people dream, generally four to six times each night (Jouvet, 1967a, $b$; Dement, 1969; Hartmann, 1973), although memories for sleep experiences are often vague and incomplete. Comparative and developmental studies of sleep suggest both an onto- and phylogenetic continuity of Rapid Eye Movement (REM) states in humans or Paradoxical Sleep (PS) in animals as the physiological concomitant and probable cause of dreaming (Kleitman, 1963; Jouvet, 1967a; Snyder, 1969). REM is present in human neonates from birth, and is found in all mammals, and in a rudimentary form in birds. The hypothesis that animals dream in fact precedes modern sleep studies by some two millenia (Bafley, 1921).

The anatomy, physiology and pharmacology of brain structures determining dreaming are well established, and have been reviewed in detail (e.g. Jouvet, 1967a; Morgane \& Stern, 1974; Hobson \& McCarley, 1977). Nonetheless, the purpose of the dream-the psychological functions served by it-remains as elusive as dreams themselves. Despite thousands of articles upon REM, its functional significance remains unknown. It is an answer residing in each of us that leaves us pondering what 
question it might address. The present paper is intended as a selective review and synthesis. Our thesis is that there may be an underlying common ground to many apparently discrepant theories of dream function, and that this common ground involves pleasure, with dreams serving both incentive maintaining purposes and further, as integrators of certain forms of cognition (the latter being based upon the former). To establish this we begin with an overview of some major theories of dream function.

While early views of dreaming may be found in the Old Testament (cf. the story of Daniel), in Greek and Roman mythology and in alchemical theory, perhaps the single most influential attempt to systematize dreams may be found in the psychoanalytic theories of Freud and his followers.

Traditional psychoanalytic views have emphasized functions related to motivational homeostasis, and the discharge of emotional impulses.

Of the dream we know as yet only that it expresses a wish fulfillment of the unconscious; and apparently the dominant preconscious system permits this fulfillment when it has compelled the wish to undergo certain distortions ... (Freud, 1900).

Thus for traditional psychoanalytic theory, the dream, through its manifest and latent content, is a means to wish fulfillment and the resolution and satisfaction of libidinal impulses.

More recent psychoanalytic theories (e.g. Hartmann, 1976; Khan, 1976) and other non-analytically oriented views have stressed information processing, learning and cognitive accommodation rather than motivational functions. One example of this is a study of patients about to enter psychotherapy (Greenberg \& Pearlman, 1976). Examination of initial sleep parameters prior to the beginning of therapy (i.e. REM amount, coherence and efficiency) proved to offer considerable predictive value regarding patient accessibility, conflicts and the probability of elopement from therapy. A second more recent study also shows reduced REM latency with psychotherapy (Karle, Hopper, Corriere, Hart \& Switzer, 1977). The psychological restructuring of therapy is, of course, one special form of learning.

Other forms of learning and adaptive functioning also appear to be reflected in REM changes. A number of recent reviews (Hennevin \& Leconte, 1977; McGrath \& Cohen, 1978) have stressed consistent increases in REM in both humans and animals immediately after learning. It appears that REM is normally increased after a variety of learning tasks, particularly when they involve relatively complex modes of solution. Conversely, interference with post trial REM selectively retards the normal acquisition process. For example, Paul \& Dittrichova (1975) report that human infants showed increased REM after learning a head turning task. They did not show this change, however, after another task which was not acquired. Hennevin \& Leconte (1977), in their extensive review, discuss a number of experiments in rats carried out by their research group. In one typical experiment rats learning an avoidance response showed correlated increases in PS, while rats not learning failed to show this change. Interference with post trial PS retarded learning, but only if administered immediately after the session. Later but equivalent amounts of PS deprivation were without effect. These examples indicate some truth to both clinically generated and experimental insights upon the nature of PS, and hence dreaming. They suggest that dreams are involved with both motivational and cognitive activity.

We propose a view which is alternative and complementary to both motivational and information processing views. Our hypothesis has its roots in recent psycho- 
analytic theory and physiological evidence. On the one hand, the psychoanalytic framework drawing upon the recent theories of Khan (1976) suggests a distinction between the dream functions and dream content. Khan argues that the dreaming experience influences behavior; however, the dream itself, as dream script or story may not necessarily be available, accessible or amenable to analysis. In the present paper, we are only incidentally concerned with manifest dream content, the so-called 'dream script'. While content may offer some clues to dream function we know of no non-anecdotal studies in which dreams have been systematically subjected to content analysis for their underlying motivational or affective structure. Such a study would require large-scale sampling of normal and psychiatric populations and well-controlled statistical procedures. Should such studies occur they might also prove helpful and possibly complementary to other approaches. Since they are not available, however, the present analysis must restrict itself accordingly. On the other hand, the physiological evidence necessarily carries with it a number of structural concerns, since it suggests that a neural'structure with at best limited plasticity and functions generates dream patterns. It might be noted that Hobson \& McCarley (1977) have, in fact, attempted to deal with possible psychobiological bases of actual dream content in a preliminary fashion. Nonetheless, this approach remains tentative and we again stress that content and function, i.e. the dream script and dream, may be fruitfully studied separately. Also, in light of several excellent reviews which have recently appeared, we will limit our discussion of the physiology and clinical neuroanatomy of sleep to some rather circumscribed aspects of the brain circuitry controlling REM.

Our aim is to present and evaluate evidence suggesting that stage REM is a primitive pleasure state which has become specialized for the control of cognition. This thesis may be broken down into component hypotheses which will be individually treated. First, we propose that based upon converging lines of psychobiological evidence, stage REM is a pleasure state. Another way of saying this is that we consider the brain state in stage REM to be equivalent to that which occurs in normal reinforcement. Second, we propose that the pleasure state involves circumscribed functions. It is involved with the integration of the qualitative and quantitative stimulus aspects of reward. We further argue that this capacity to respond selectively to reinforcement may mediate certain forms of learning involving the formation of afferent associations (i.e. S-S or cognitive learning). This thesis, although not original, since it draws upon both motivational and cognitive interpretations, nonetheless offers a novel synthesis of neo-Freudian and information processing views of sleep, and suggests a mechanism by which both theories might ultimately be correct and complementary in their view of dreaming. This view also offers psychobiological evidence for the truth of certain psychoanalytic propositions. The evidence bearing upon the present thesis derives from a number of seemingly unrelated sources which have previously not been brought to bear upon this issue in a systematic manner. Included among these areas are: developmental psychobiology, comparative studies of learning across species and physiologic evidence from brain stimulation. Studies of these topics and their relation to REM will be summarized in course, and their relation to the REMpleasure-cognition hypothesis shown.

\section{The ontogenesis of dreaming}

Any description of the functional significance of sleep and dreaming must take account of its ontogenesis and functional concomitants in neonates. Developmental studies are both useful and necessary because they permit the study of phenomena in 
their most elementary form, prior to influences such as learning or maturation. Moreover, and for related reasons, grounds exist for expecting closer continuity and more readily established functional relationships for neonates and other species than for more mature animals. Finally, neonatal studies provide a baseline for comparing systematic psychobiological changes over time. Since many changes occur, developmental studies allow unobtrusive identification of covarying and hence potentially interrelated phenomena.

A number of aspects of neonatal sleep are signal. REM is relatively more frequent in neonates and only gradually declines to adult levels. Also, neonatal REM lacks the sequential structure of later sleep. While adult REM occurs only after a transition from stages four through one, neonatal REM may occur from waking or directly from stage four. While the recording and analysis of these changes is somewhat problematic-EEG patterns are not as well defined as in adults, these relationships, nonetheless, have been upheld in a number of laboratories using both behavioral and electrophysiological criteria (Roffwarg, Dement \& Fisher, 1964; Emde \& Metcalf, 1970).

It is of considerable interest that the major behavioral concomitants of REM in neonates are signs of pleasure and consummatory behavior. Neonatal REM is accompanied by episodic bursts of smiling. Wolff (1959) reported a high correlation between smiling and 'irregular sleep', and in fact suggested this might represent a primitive affective state. Recent longitudinal studies indicated smiling coincident with active sleep (REM) as early as 1 day post partum. This has been confirmed repeatedly and both brief reflexive and slow well-organized smiles occur at least 2 weeks prior to the initiation of social behavior and social expression (e.g. Prechtl, 1974). Independent confirmation of both the 'endogenous' (i.e. non-social) nature of smiling and its correlation with REM have since been found in several other studies (Roffwarg et al., 1964; Tcheng \& Laroche, 1965; Petre-Quadens, 1966; Prechtl, 1974). Edme \& Metcalf (1970) noted smiling in neonates which could not be related to 'gas' as had been hypothesized by others.

Suckling has also frequently been observed during REM in infants (Nystrom, Bandmann \& Valentin, 1977). In one recent and extremely thorough categorization of neonatal sleep patterns, three clusters of behavior involving crying, smiling and startle responses were found to exist which were mathematically independent of each other. The second of these three behavioral clusters uniquely included REM, smiling and suckling (Nystrom et al., 1977). It would therefore appear that smiling and possibly pleasure are 'endogenous' to the structure of sleep, and specialized in REM.

Related findings suggest a high coincidence of PS and pleasure responding in other species. For example, grooming and suckling are generally followed by increased PS in cats and rats (Jouvet-Mounier, Astic \& Lacote, 1970). It has been hypothesized that 'sucking REM' may be a non-nutritional activity since kittens will suckle continuously for several hours in stage REM (Morgane, 1972).

Finally, additional developmental data suggest a longitudinal relationship of REM and pleasure, although smiling is replaced by other responses. Studies of infants, children and adults suggest that the later behavioral accompaniments of REM include penile erections in males and clitoral enlargement in females. These studies are complicated by the tonic motor inhibition accompanying adult REM; however, the findings appear quite robust. One conclusion from these studies is that REM is involved in pleasure. At very least the above studies indicate that it is a pleasure concomitant. REM may also be involved in the actual control of pleasure. 
Evidence for this would require either direct manipulation of REM, and subsequent changes in pleasure, or direct manipulation of pleasure with changes in REM. Such studies are discussed below. The initial pleasure response is oral and facial (smiling) but it is replaced by an adult genital response. This observation fits well into classical Freudian theory, but changes seem not to be restricted to those predicted by Freud. We have already mentioned changes in REM in association with psychotherapy and learning. Maturation may involve specialization of pleasure for both cognitively and behaviorally circumscribed activities. These studies (and this last hypothesis) receive further support from phylogenetic studies of the evolution of intelligence.

\section{A behavioral analysis of reward}

Just as ontogenetic studies offer the possibility of longitudinal study and correlation of psychobiological relationships, so also do phylogenetic studies, although on an evolutionary scale. By comparing different species with respect to correlated changes in brain and behavior it is again possible to identify unobtrusively possible structural correlates for species specific behavioral and motivational adaptations. We have hypothesized, based upon neonatal studies, that REM may represent a primitive pleasure state. Comparative learning theory has addressed both the phylogenetic roots of reward and the evolution of intelligence. Once again correlated changes of REM and pleasure are evident.

These changes in REM and reward can be understood within a framework of hedonic heterogeneity which parallels the phylogeny of PS. Reward has often been naively assumed to represent an essentially homogeneous set of functions and operations across all species. Skinner (1959) speaks of the difficulty of analysis of species characteristics from response records. Other proponents of this view include Thorndike (1911) and Pavlov (1928). If this view of reward is correct then clearly the biological roots of pleasure are phylogenetically very old. In fact, however, a number of recent empirical studies of reward and punishment suggest this view of reward may be naïve in a number of ways. One criticism of this view has come from ethologically oriented psychologists while a second has come from comparative learning theorists.

One of the major 'ethological' criticisms of the views of Skinner and others has come from Seligman (1970) who terms the former a 'general process' account. By such a view, any stimulus is equally associable with any response in a given organism. Seligman points out that while reward clearly has a number of general and species independent aspects, it may also have some species specific properties. Based upon the 'ethological drift' of certain responses towards prototypical and species specific consummatory responses (Breland \& Breland, 1961), and apparently large stimulus dependent differences in the rate of formation of classically conditioned aversive responses to poison after the ingestion of a novel food, Seligman has suggested that the postulate of arbitrary associability may not be general. Rather, stimuli and reinforcers may show 'belongingness' or differential 'preparedness' of associability. Rozin has recently suggested a similar view of learning, in which animals show unique and species specific patterns of response to motivationally significant stimuli which often then show a differential 'accessibility' for other forms of learning (Rozin \& Kalat, 1971; Rozin, 1976). If such views as these are correct even in part it implies that reward functions are potentially highly specific, and may require careful analysis both within and across species, particularly with regard to correlated changes in incentive learning and PS. 
Further evidence for the complexity, heterogeneity and differential accessibility of reward across species functions comes from comparative learning theory (e.g. Bitterman, 1965, 1975). Using species as a dependent variable of interest and a large variety of learning tasks, qualitative and species specific differences in instrumental performance were observed between fish, turtles, pigeons and rats. These differences were interpreted as indicating the operation of possibly two distinctive reward mechanisms. On the one hand, organisms such as fish and turtles showed a single form of learning that might best be described as primitive stimulus-response habit formation, a form of reward possibly mediated by drive reduction. On the other hand, birds and rats showed an added ability to respond to rewards as incentive stimuli. Particular attention to this second form of reward (vide infra) suggests that it may be related to PS.

Looking first at simple habit formation, a variety of experiments have indicated that fish and turtles can learn simple operant schedules of behavior but that they often fail to respond to shifts in reward magnitude and quality with appropriate response shifts, i.e. altered response latencies or rates. In one experiment when magnitude of reward was decreased for a fish it failed to alter its behavior. Turtles, on the other hand, responded by assuming the response latency and magnitude appropriate to an unshifted control (Bitterman, 1969; Pert \& Bitterman, 1970). Rats and other mammals, however, showed rather different responses to reward shifts. Elliott (1928) and Tinklepaugh (1932) examined the effects of altered reward quality while Crespi (1942) examined the effects of altered reward quantity upon performance (note also more recent studies, e.g. Gonzales \& Bitterman, 1969; Eisenberger, Frank \& Cortis-Park, 1975). In all of these studies an emotional response accompanied the shift in reward. This emotional response assumed a number of forms. Monkeys with shifted rewards, for example, showed visible agitation (screaming, excitability), and in addition reward shifted rats typically showed response decrements not seen in fish or turtles. Rather than assuming an appropriate rate of response, rats would perform even more slowly than controls once their reward had been shifted to a smaller magnitude. This was termed a depression effect. Later increases in reward subsequent to an initial response depression caused a converse phenomenon of behavioral elation (i.e. responding above both previous and control levels). Thus, rats and other mammals appeared to learn about the stimulus properties of rewards and to respond emotionally to alterations in these reward stimulus properties in a way fish and turtles did not. Table 1 summarizes these findings.

Table 1. Relationship of $P S$ and incentive-phylogenetic

\begin{tabular}{lccc}
\hline \multicolumn{1}{c}{ Species } & $\begin{array}{c}\text { Instrumental } \\
\text { learning }\end{array}$ & $\begin{array}{c}\text { Crespi incentive } \\
\text { effect and/or } \\
\text { latent learning }\end{array}$ & PS \\
\hline Fish (goldfish) & + & - & - \\
Turtle & + & + & - \\
Bird (pigeon) & + & + & + \\
Rat & + & + & + \\
Rat (PS deprived) & + & + \\
\hline
\end{tabular}

† Studies based upon Bitterman and collegues (see text).

While incentive shifts of the sort Crespi described remain a primary difference in learning ability at a species level, other related phenomena may also show a similar division along identical species lines. For example, the most radical form of incentive 
shift at both a qualitative and quantitative level clearly involves a change from no (i.e. zero level) reward to some tangible quality and quantity of reward. This sort of incentive shift known also as latent learning is found in rats (Thistlethwaite, 1951; Bitterman, 1975). Finally, rats extinguish more rapidly to large rewards than to small, while the reverse is true of fish. This may imply the existence of a Crespi effect in extinction (Gonzalez \& Bitterman, 1969).

Reward functions then are far from homogeneous across species. Rather, they involve the interaction of at the very least two processes. On the one hand, a rather simple and perhaps drive-like reward mechanism appears to exist in apparently all vertebrates which have been examined to date. This mechanism mediates simple instrumental learning, and simple reward shifts, and may be considered a 'general process' mechanism. On the other hand, an incentive mechanism, seen in the Crespi effect, in certain forms of facilitated extinction, and in cognitive phenomena appears to exist selectively in only a few species (rats and possibly birds). This incentive mechanism, by allowing increasingly specialized and specific encoding of reward permits increasingly complex modes of problem solution and may be considered the sort of specialization Rozin has spoken of (Rozin, 1976). This finding of a species specific reward mechanism offers one possible approach to a phylogenetic description of behavior and its sleep correlates.

\section{The biology of the dream}

We have seen that learning about reward is a phylogenetically discontinuous event. Indeed, while many species show behavioral adaptations to the presence or alteration of reward only few appear to respond with emotional, i.e. elated or depressed, patterns of response. It is therefore of interest that a close parallel exists phylogenetically between the capacity for this latter class of responses to reward on the one hand and the sleep stage of paradoxical sleep (PS) on the other. PS has been observed only in mammals and in relatively brief episodes in birds (Derbyshire, Rempel, Forbes \& Lambert, 1936; Kleitman, 1963; Snyder, 1966; Jouvet, 1967b; Hartmann, 1973), exactly the same species that are behaviorally sensitive to incentive contingencies.

The biological foundations of paradoxical sleep are still only partly understood but it appears that both tonic and phasic aspects of this sleep state are under the inhibitory control of the dorsal pontine noradrenergic nucleus, the locus coeruleus (L.C.) or A6, nucleus. Recent studies based on unit recordings within the L.C. suggest that the nucleus is inactive during PS (e.g. Hobson \& McCarley, 1977; Foote, Bloom \& Schwartz, 1978), while more ventrally located cells of the paramedian reticular formation are conversely more active (op. cit.). Thus locus coeruleus activity appears to inhibit many aspects of PS. Other aspects of paradoxical sleep (possibly, for example, hippocampal theta) may be under the partial control of the giganto-cellular tegmental field (Hobson, McCarley \& Wyzinski, 1975; McCarley \& Hobson, 1975; note, however, Siegel \& McGinty, 1977; Vertes, 1977).

The locus coeruleus has been a site of particular interest to physiologists and pharmacologists because of the neurochemically homogeneous nature of its cells and because anatomical studies indicate the cells innervate a number of areas (cerebellum, hippocampus, broad areas of the cortex and diencephalon) which could control many aspects of motivated behavior (Fuxe, Hokfelt \& Ungerstedt, 1970; Lindvall \& Bjorklund, 1974). We have already noted that animals that do not show incentive phenomena (Bitterman, 1975) do not show paradoxical sleep (Jouvet, 1967b) and 
that the locus coeruleus may be critically involved in dreaming. The question then arises if it might be possible to implicate the locus coeruleus or its associated neurophysiological activity more directly in the control of incentive. In fact, several lines of evidence support the hypothesis of a relationship between paradoxical sleep and incentive.

The first line of evidence is based upon the recording of L.C. activity during the normal waking activity of primates and other animals. This relatively unobtrusive technique has provided evidence for L.C. involvement in sensory encoding related to motivation. Recent work from the laboratory of Floyd Bloom (Foote et al., 1978) suggests the locus coeruleus responds to all arousing stimuli. However, it quickly habituates to motivationally neutral stimuli. On the other hand, it continues to respond to appetitive and aversive stimuli, and will show enhanced firing to conditioned stimuli paired with the above. Thus, it is an ideal sensory gate for stimuli with differential incentive properties.

A further means of extending the present correlational findings is to examine directly the effects of PS manipulations upon incentive mediated learning and performance. Several recent studies have suggested that this approach is a useful one in identifying a causal relationship between these two variables, and that interference with PS produces concomitant changes in uniquely mammalian learning patterns. Such changes are highly task specific with cognitive and incentive learning being most affected. For example, both latent learning and the related phenomenon of latent extinction are disrupted subsequent to PS deprivation. Since the former task involved a below normal response pattern while the latter produced supra normal responding i.e. two oppositely signed responses, it follows that non-specific activation or depression effects cannot readily account for these findings (Pearlman, 1971; Greenberg \& Pearlman, 1974; Pearlman \& Becker, 1974). It might also be noted that other tasks that are typically used as species filters, e.g. habit reversal or probability matching, also showed a return to phylogenetically more primitive modes of solution after selective REM deprivation (Greenberg \& Pearlman, 1974).

Studies on human populations also support this hypothesis; REM deprivation selectively interfered with a problem solving task involving creative rather than rote solutions. Reports on REM changes with psychotherapy have already been noted. It might be concluded that interference with REM produced a loss of incentive related activities (Lewin \& Glaubman, 1975).

The recent work of Mason and colleagues in the laboratory of Dr Iversen (Mason \& Iversen, 1978) should also be noted. Gonzales \& Bitterman (1969) posit the incentive depression (i.e. Crespi) effect as a major control of extinction in the rat. Rats with lesions of the locus coeruleus and dorsal bundle in fact showed enhancement of resistance to extinction and behaved in a manner predicted for non-incentive animals (Bitterman, 1969). It might be argued that this increased resistance represented a failure to encode altered incentive properties that normally control Crespi effect associated behavioral depression and facilitate extinction.

\section{Physiological evidence}

Perhaps even more telling evidence, however, may be found from an examination of several recent studies involving electrical stimulation of the central nervous system. In the self-stimulation task animals directly self-administer electrical stimulation to central reward neurons and it may be assumed that at least some of the neurons excited by this stimulation are rewarding if the behavior is maintained 
over time. Studies employing brain stimulated behavior including self-stimulation indicate a functional complementarity between brain stimulated reinforcement and paradoxical sleep. Interference with paradoxical sleep produces increases in selfstimulation rates (i.e. increased hedonic drive) and conversely self-stimulation may reduce the need for paradoxical sleep in both normal and paradoxical sleep-deprived subjects (Steiner \& Ellman, 1972). In fact, while there exists a near universal drive to regain paradoxical sleep after deprivation, this is eliminated through self-stimulation (Cohen, Edelman, Bowen \& Dement, 1972; Steiner \& Ellman, 1972). Thus, it may be seen that intracranial reward within the medial forebrain bundle, the brain system which incorporates major fiber bundles from the locus coeruleus, appears to be able to substitute for paradoxical sleep.

Anatomical studies further confirm this, since the locus coeruleus which mediates some aspects of paradoxical sleep supports very high levels of self-stimulation behavior (Crow, Spear \& Arbuthnott, 1972; Ritter \& Stein, 1973; Ellman, Ackermann, Farber, Mattiace \& Steiner, 1974). In fact, rates of between 15,000 and 20,000 bar-presses per hour have been reported for locus coeruleus self-stimulation (Ellman et al., 1974). To our knowledge this is the highest rate of operant bar pressing ever reported for any reinforcer. Other studies also indicate that the major ascending fiber bundles from the noradrenergic locus coeruleus will support robust self-stimulation (German \& Bowden, 1974; Rolls, 1975; Stein, 1968, 1975). Examination of antidromic electrical activation of the L.C. by brain stimulation reward indicates that many brain sites cause L.C. firing in conjunction with self-stimulation (German \& Fetz, 1976). In the same study occasional L.C. firing was noted in conjunction with foods such as raisins or bananas which might be considered incentives. This is also consistent with the report of Foote et al. (1978). REM is clearly complex and the locus coeruleus is one, but only one, of many control mechanisms for REM. Conversely, there exist many other control mechanisms for brain stimulation (e.g. Routtenberg, 1978). Lesions of the L.C. (op. cit.) apparently have only a minor effect upon more rostral self-stimulation. Since the L.C. is proposed as a mediator of one of various forms of reinforcement this is not necessarily contradictory.

One possible extension of the present hypothesis would suggest that if any nonnoradrenergic incentive regulating system could be identified then it might also be involved in REM. Crow (1976) has suggested that dopamine may be involved in incentive-reward. It is therefore of interest that PS deprivation may induce a super sensitivity of DA receptors (Tufik, Lindsey \& Carlini, 1978). Since direct effects of DA agonists upon PS may be difficult to observe (e.g. Loew, Vigouret \& Jaton, 1976) this may be indirectly mediated. We stress the locus coeruleus might be directly or indirectly involved in controlling circumscribed aspects of REM that may directly include pleasure and subsequently also the control of cognition.

\section{Clinical evidence}

A number of studies on humans confirm and expand these findings. Increasing REM pressure through selected sleep deprivation results in a state of hyperactivity, increased sexual drive, increased appetite, irritability, distractability and cognitive disruptions (Fisher \& Dement, 1963; Agnew, Webb \& Williams, 1967; St Laurent, 1971). Increased hedonic drive and decreased cognition are predicted from the present model. Occasionally euphoria and grandiosity are also present, with symptoms almost identical with clinical descriptions of manic episodes. Total sleep deprivation disturbs the mood of normal individuals, but in patients who suffer from endogenous 
depression a therapeutically imposed total sleep deprivation seems to cause some improvement (Van den Burg \& Van den Hoofdakker, 1975). Endogenous depressive patients seem also to respond well to selective REM deprivation (Vogel, Thurmond, Gibbons, Sloan \& Walker, 1975).

Other clinical studies offer further parallels to animal studies and support the present thesis. Greenberg, Maler \& Pearlman (1969) have reported the euphoriant gas, nitrous oxide, has an effect in humans similar to the reported effects of brain stimulation upon PS in rats. In both cases REM rebound was reduced. All subjects reported increased pleasurable sensations and mood after the drug and showed reduced REM rebound; the only subject to experience dysphoria showed augmented rather than reduced REM. In addition, Cartwright et al. (1975) have noted selected decreases in REM in subjects showing emotional involvement when recounting dream materials. Several studies therefore suggest that the elegant brain stimulation work of Steiner and colleagues may have clinically meaningful counterparts. Additional pharmacological studies will be reviewed in course. The present studies suggest the existence of correlation between a neural system subserving paradoxical sleep on the one hand and incentive functions on the other hand.

While brain stimulation offers one means of artificially activating central pleasure mechanisms, other studies in which the brain's pleasure mechanism is artificially activated or depressed also support the present hypothesis. Other agents which allow for such an artificial activation are by and large pharmacothymic in nature, i.e. stimulant drugs which have a clear hedonically positive aspect that motivates their initial use. Such drugs include a wide variety of stimulant euphoriant agents, for example, cocaine, amphetamines and possibly morphine. Both human and animal studies suggest that just as electrical stimulation may reduce the nced for paradoxical sleep, so also may the chemically induced pleasure of stimulant drugs. Drugs of abuse such as cocaine (Post, Gillin, Wyatt \& Goodwin, 1974), methylphenidate and amphetamines (Rechtschaffen \& Maron, 1964; Baekeland, 1967; Shimizu \& Himwich, 1968) all produce decreases in REM sleep and increased latencies to initial REM episodes. Morphine and heroin have been reported to have similar effects (Khazan \& Sawyer, 1964; Kay, Eisenstein \& Jasinski, 1968; Lewis, Oswald, Evans, Akindele \& Tompsett, 1970). Thus, pleasure augmenting agents both electrical and pharmacological have been shown to substitute for paradoxical sleep.

It follows from the present hypothesis that a group of depressant drugs should have largely converse pharmacological and neurophysiological effects. Specifically, drugs which increase REM should decrease hedonic responsivity, and drugs that are known to reduce incentive functions should increase REM. Reserpine has been reported to produce a behavioral syndrome which is clinically indistinguishable from endogenous depression (Mendels \& Frazer, 1974), and this drug in fact increases REM sleep (Hartmann, 1966). Moreover, decreased REM latency also typically follows reserpine administration. Thus, a variety of studies from several fields all suggest a relationship between REM and incentive which may be viewed in essence as a functional substitution of one for the other. High pleasure states are associated with less REM, and low pleasure states with substantially increased REM.

\section{Discussion}

The present paper was prompted by a specific and highly circumscribed set of concerns: (1) the possible evolutionary significance of the REM state as a psychobiological antecedent to complex learning phenomena, (2) the possible role of PS in 
hedonic control and (3) the relationship of PS and disrupted hedonic self-regulation. In many ways this limited scope allowed a useful categorization of much data. We have argued for involvement of the noradrenergic A6 nucleus in the Crespi effect and more generally in incentive. Its control of sleep, its electrophysiological concomitants and stimulation studies all suggest a consistent role. We have suggested that the existence of Crespi-like effects, particularly extreme cases of the latter (i.e. latent learning), are a necessary antecedent for cognitive (i.e. S-S) learning. Finally, we have suggested that since PS is a specialized EEG state it is possible to localize the above behavioral functions into the discrete CNS areas mediating paradoxical sleep. These hypotheses, while novel, have roots in many previous theories. The present section will review these briefly. At the turn of the century Freud suggested that dreams represented motivational archetypes in which unacceptable impulses were symbolically acted out. Thus dreams served a pleasure discharging function, and this is quite similar to the current hypothesis. While the present hypothesis makes no statement as to the relationship of manifest dream content and motivation, it nonetheless shares an overall concern for the role of the dream in motivational self-regulation.

More recent work from several laboratories (notably the work of Pearlman \& Greenberg, 1970; Hartmann, 1976; Fishbein \& Gutwein, 1977) had addressed the role of dreams in information processing. Since these theories assume that information processing results in altered ability to adapt to environmental conditions, there is again some similarity to the present views, although we stress motivational rather than informational aspects of the adaptive process.

Hartmann recently has also offered a chemical theory of the dream as a restorer of noradrenergic function (Hartmann, 1973). Several other authors have independently arrived at this conclusion (e.g. Vogel, Traub, Ben-Horin \& Meyers, 1968; Morgane $\&$ Stern, 1974). The present review suggests that patency of the noradrenergic L.C. is specifically related to incentive reward, a conclusion also found in Stein $(1968,1975)$. In a series of papers on the psychopharmacology of reward and schizophrenia he and his co-workers have suggested both incentive and possibly cognitive functions for the NA bundle which has been also suggested to be involved in PS. Thus, brain stimulation studies, psychoanalytic studies and studies of dreaming lead to identical concerns and conclusions. The physiological state of REM is a psychobiological equivalent to the motivational state of incentive reward.

Rozin (1976) has suggested that one means of achieving increased psychobiological adaptability is through 'accessing' of specific and specialized capacities. One form of such accessing was seen in studies of comparative behavior.

The concept of accessing may be useful in summarizing some of the relationships of REM, pleasure and cognition which have been outlined. Two related forms of accessing may underlie the proposed relationships. On the one hand, REM is initially associated with smiling and oral behaviors. REM may represent a primitive pleasure state which becomes specialized for incentive discrimination. Incentive discrimination allows for finer behavioral accommodations in reward, higher pleasure functions (incentive shifts) and, in principle, for sufficiently fine behavioral control for complex learning accommodations. These changes may lie at the roots of cognitive phenomena. The second and related use of accessing is neurological and involves the locus coeruleus. We have pointed out that sleep initially is associated with oral activity. The L.C. appears to fire differentially to certain appetitive stimuli. The L.C. may encode the differential properties of food incentives. It may in principle be accessed 
to other stimuli and hence, in time, subserve general incentive related discrimination functions. Thus, it may possess at a neural level the requisite sensory capacity for the REM related incentive accessing. Motivation, particularly incentive motivation, involving fine discriminations of the stimulus properties of reinforcers may be at the root of cognition, and may act through a specialized sleep state.

Clearly, many aspects of dream-incentive relationships await additional empirical study. At the very least the hypotheses which have been proposed are testable, and capable of generating additional experiments. It is fitting perhaps to realize that the core of human experience is bounded by both its days and its nights, and that we are products of both light and darkness-our waking hours and our dreams.

\section{References}

Agnew, H. W., Webb, W. B. \& Williams, R. L. (1967). Percept. Mot. Skills 24, 851.

Baekeland, F. (1967). Psychopharmacologia (Berl.) 11, 388.

Bailey, C. (1921) (transl.). Lucretius Carus, T., De rerum natura. Oxford: Clarendon Press.

Bitterman, M. E. (1965). Scient. Am. 212, 92.

Bitterman, M. E. (1969). Am. Psychol. 24, 444.

Bitterman, M. E. (1975). Science, 188, 699.

Breland, K. \& Breland, M. (1961). Am. Psychol. 16, 681.

Cartwright, R. D., Lloyd, S., Butters, E., Weiner, L., McCarthy, L. \& Hancock, J. (1975). Psychophysiol. 12, 561.

Cohen, H., Edelman, A., Bowen, R. \& Dement, W. C. (1972). Sleep Res. 1, 158.

Crespi, L. P. (1942). Am. J. Psychol. 55, 467.

Crow, T. J. (1976). In Brain Stimulation Reward (A. Waquier and E. T. Rolls, Eds). Amsterdam: Elsevier/North Holland, p. 587.

Crow, T. J., Spear, P. J. \& Arbuthnott, G. W. (1972). Brain Res. 36, 275.

Dement, W. C. (1969). In Sleep, Physiology and Pathology (A. Kales, Ed.). Philadelphia: Lippincott Co., p. 245.

Derbyshire, A. J., Rempel, B., Forbes, A. \& Lambert, E. F. (1936). Am. F. Physiol. 116, 577.

Eisenberger, R., Frank, M. \& Cortis-Park, D. (1975). F. Exp. Psychol.: Anim. Behav. Proc. $1,346$.

Elliott, M. H. (1928). Univ. Calif. Publ. Psychol. 4, 19.

Ellman, S. J., Ackermann, R. F., Farber, J., Mattiace, L. \& Steiner, S. S. (1974). Physiol. Psychol. 2, 31.

Emde, R. N. \& Metcalf, D. R. (1970). Y. Nerv. Ment. Dis. 150, 376.

Fishbein, W. \& Gutwein, B. M. (1977). Behav, Biol. 19, 425.

Fisher, C. \& Dement, W. C. (1963). Am. F. Psychiatry 119, 1160.

Foote, S. L., Bloom, F. E. \& Schwartz, A. (1978). Neurosci. Abstr. 4, 272.

Freud, S. (1900). In The Standard Edition of the Complete Psychological Works of Sigmund Freud, Vol. 5 (J. Strachey, Ed.). London: Hogarth Press and The Institute of Psychoanalysis.

Fuxe, K., Hokfelt, T. \& Ungerstedt, U. (1970). Int. F. Neurobial. 13, 93.

German, D. C. \& Bowden, D. M. (1974). Brain Res. 73, 381.

German, D. C. \& Fetz, E. E. (1976). Brain Res. 109, 497.

Gonzalez, R. C. \& Bitterman, M. E. (1969). F. Comp. Physiol. Psychol. 67, 94.

Greenberg, R., Mahler, D. \& Pearlman, C. A. (1969). Arch. Gen. Psychiatry 21, 691.

Greenberg, R. \& Pearlman, C. A. (1974). Perspect. Biol. Med. 17, 513.

Greenberg, R. \& Pearlman, C. A. (1976). Am. F. Psychiatry 133, 1147.

Hartmann, E. (1966). Psychopharmacol. 9, 242.

Hartmann, E. (1973). The Functions of Sleep. New Haven: Yale University Press.

Hartmann, E. (1976). Int. F. Psycho. Anal. 57, 331.

Hennevin, E. \& Leconte, P. (1977). Physiol. Behav. 18, 307.

Hobson, J. A. \& McCarley, R. W. (1977). Am. F. Psychiatry 134, 1335.

Hobson, J. A., McCarley, R. W. \& Wyzinski, P. W. (1975). Science 189, 55.

Jouvet, M. (1967a). Physiol. Rev. 47, 117.

Jouvet, M. (1967b). Scient Am. 216, 62. 
Jouvet-Mounier, D., Astic, L. \& Lacote, D. (1970). Develop. Psychobiol. 2, 216.

Karle, W., Hopper, M., Corriere, R., Hart, J. \& Switzer, A. (1977). Physiol. Behav. 19, 419.

Kay, D. C., Eisenstein, R. B. \& Jasinski, D. R. (1968). Psychophysiol. 5, 204.

Khan, M. M. R. (1976). Int. F. Psycho-Anal. 57, 325.

Khazan, N. \& Sawyer, C. H. (1964). Psychopharmacologia 5, 457.

Kleitman, N. (1963). Sleep and Wakefulness, revised 2nd ed. Chicago: University of Chicago Press.

Lewin, I. \& Glaubman, H. (1975). Psychophysiol. 12, 349.

Lewis, S. A., Oswald, I., Evans, J. I., Akindele, M. O. \& Tompsett, S. L. (1970). Electroenceph. Clin. Neurophysiol. 28, 374.

Lindvall, O. \& Bjorklund, A. (1974). Acta Physiol. Scand. (Suppl.) 412, 1.

Loew, D. M., Vigouret, J. M. \& Jaton, A. L. (1976). Postgrad. Med. Э. (Suppl.) 52, 40.

McCarley, R. W. \& Hobson, J. A. (1975). Science 189, 58.

McGrath, M. J. \& Cohen, D. B. (1978). Psychol. Bull. 85, 24.

Mason, S. T. \& Iversen, S. D. (1978). Physiol. Behav. 21, 1043.

Mendels, J. \& Frazer, A. (1974). Arch. Gen. Psychiatry 30, 447.

Morgane, P. J. (1972). In Sleep and the Maturing Nervous System (C. D. Clemente, D. P. Purpura \& F. E. Mayer, Eds). New York: Academic Press, p. 219.

Morgane, P. J. \& Stern, W. C. (1974). In Advances in Sleep Research, Vol. 1 (E. Weitzman, Ed.). New York: Spectrum, p. 1.

Nystrom, M., Bandmann, Y. \& Valentin, A. (1977). Psychol. Res. Bull. Lund Univ. $17,1$.

Paul, K. \& Dittrichova, J. (1975). In Sleep 1974 (P. Levin, \& W. D. Koella, Eds) (2nd European Congress on Sleep Research, Rome 1974). Basel, Switzerland: Karger, pp. 388-390.

Pavlov, I. P. (1928). Conditioned Reflexes. London: Oxford University Press.

Pearlman, C. A. (1971). Psychon. Sci. 25, 135.

Pearlman, C. A. \& Becker, M. (1974). Physiol. Psychol. 2, 509.

Pearlman, C. A. \& Greenberg, R. (1970). Psychiatry Med. 1, 261.

Pert, A. \& Bitterman, M. E. (1970). Learn. Motiv. 1, 121.

Petre-Quadens, O. (1966). F. Neurol. Sci. 3, 151.

Post, R. M., Gillin, J. C., Wyatt, R. J. \& Goodwin, F. K. (1974). Psychopharmacologia (Berl.) 37, 59.

Prechtl, H. F. R. (1974). Brain Res. 76, 185.

Rechtschaffen, A. \& Maron, L. (1964). Electroenceph. Clin. Neurophysiol. 16, 438.

Ritter, S. \& Stein, L. (1973). F. Comp. Physiol. Psychol. 85, 443.

Roffwarg, H. P., Dement, W. C. \& Fisher, C. (1964). In Problems of Sleep and Dreams in Children, Vol. 2 (E. Harmis, Ed.). International Series of Monographs on Child Psychiatry. New York: Macmillan, p. 60.

Rolls, E. T. (1975). The Brain and Reward. Elmsford, New York: Pergamon Press.

Routtenberg, A. (1978). Scient. Am. 239, 154.

Rozin, P. (1976). In Progress in Psychobiology and Physiological Psychology, Vol. 6 (J. M. Sprague \& A. N. Epstein, Eds). New York: Academic Press, p. 245.

Rozin, P. \& Kalat, J. W. (1971). Psychol. Rev. 78, 459.

St Laurent, J. (1971). Canad. Psychiat. Assoc. F. 16, 327.

Seligman, M. E. P. (1970). Psychol. Rev. 77, 406.

Shimizu, A. \& Himwich, H. E. (1968). Psychopharmacologia (Berl.) 13, 161.

Siegel, J. M. \& McGinty, D. J. (1977). Science 196, 678.

Skinner, B. F. (1959). In Psychology: A Study of a Science, Vol. 2 (S. Koch, Ed.). New York: McGraw-Hill, p. 359.

Snyder, F. (1969). In Sleep, Physiology and Pathology (A. Kales, Ed.). Philadelphia: Lippincott, p. 266.

Snyder, S. F. (1966). Am. F. Psychiatry 123, 121.

Stein, L. (1968). In Psychopharmacology: Review of Progress, 1957/1967 (D. H. Efron, Ed.). Washington, D.C.: U.S. Government Printing Office, p. 105.

Stein, L. (1975). In Nebraska Symposium on Motivation (J. R. Cole \& T. B. Sonderegger, Eds). Lincoln: University of Nebraska Press, p. 113.

Steiner, S. S. \& Ellman, S. J. (1972). Science 177, 1122.

Tcheng, F. C. Y. \& Laroche, J. L. (1965). Acta Psychol. $24,1$.

Thistlethwaite, D. (1951). Psychol. Bull. 48, 97.

Thorndike, E. L. (1911). Animal Intelligence: Experimental Studies. Macmillan: New York. 
Tinklepaugh, O. L. (1932). Y. Comp. Psychol. 13, 207.

Tufik, S., Lindsey, C. J. \& Carlini, E. A. (1978). Pharmacology 16, 98.

Van den Burg, W. \& Van den Horfdakker, R. H. (1975). Arch. Gen. Psychiatry 132, 1121.

Vertes, R. P. (1977). Brain Res. 128, 146.

Vogel, G. W., Thurmond, A., Gibbons, P., Sloan, K. \& Walker, M. (1975). Arch. Gen. Psychiatry 32, 765.

Vogel, G. W., Traub, A. C., Ben-Horin, P. \& Meyers, G. M. (1968). Arch. Gen. Psychiatry $18,301$.

Wolff, P. H. (1959). Psychosom. Med. 21, 110. 